\title{
ORGANISMO E HISTORIA. ELEMENTOS PARA LA COMPRENSIÓN DE LA NATURALIZACIÓN DE LA HISTORIA EN NIETZSCHE
}

\author{
Organism and history. Elements for the understanding of the \\ naturalization of history in Nietzsche
}

\author{
Zaida Olvera \\ Universidad Autónoma del Estado de Morelos (México)
}

\begin{abstract}
Resumen: Nietzsche utiliza supuestos de las ciencias de la vida para construir conceptos fundamentales de su pensamiento tales como el de 'voluntad de poder' o el de 'fuerza'. Las ciencias de la vida son, asimismo, bases fundamentales para comprender la lectura nietzscheana de fenómenos sociales. A la empresa de interpretar los fenómenos sociales en función de los supuestos de las ciencias de la vida Nietzsche la llama naturalización (Vernatürlichug) de lo humano. En este trabajo pondré de relieve los elementos que componen la empresa 'naturalizante' en relación a la historia. En concreto, mostraré que un cierto giro en la noción de 'organismo' explica la comprensión, por parte de Nietzsche, de la temporalidad de los eventos históricos.
\end{abstract}

Palabras clave: fuerza - variación - desarrollo - individuo

ABSTRACT: Nietzsche took life sciences as a basis to build up some of his most important concepts such as 'will to power' or 'force'. Accordingly, life sciences are important to understand Nietzsche's philosophy in general. Nietzsche called naturalization (Vernatürlichug) of what is human the study of social phenomena through life science concepts. In this paper I will point out the elements composing this philosophical enterprise of 'naturalization' of the human. More explicitly, I will show that a certain turn in the notion of 'organism' explains Nietzsche's understanding of the temporality of historical events.

Keywords: force - variation - development - individual 
Hoy en día se ha demostrado con suficiencia la deuda intelectual contraída por Nietzsche con las ciencias de la vida de su época. Basta con echar una mirada a diversos trabajos en donde se expone la discusión en filigrana que Nietzsche sostuvo con fisiólogos, teóricos celulares y de la evolución, anatomistas, etc. ${ }^{1}$

Dichos estudios han revelado que Nietzsche utiliza supuestos de las ciencias de la vida para constituir conceptos fundamentales de su pensamiento tales como el de «voluntad de poder» o el de «fuerza». Las ciencias de la vida son, asimismo, bases fundamentales para comprender la lectura nietzscheana de fenómenos sociales ${ }^{2}$. A la empresa de interpretar los fenómenos sociales a en función de los supuestos de las ciencias de la vida Nietzsche la llama «naturalización» (Vernatürlichug) de lo humano ${ }^{3}$. Por eso Nietzsche afirma: « [...] En lugar de valores morales, valores naturalistas. Naturalización de la moral. En lugar de "sociología", una doctrina de las formaciones de dominio. $[\ldots]^{4} . \gg$

En este trabajo pondré de relieve los elementos que componen la empresa «naturalizante» en relación a la historia. En concreto, mostraré que un cierto giro en la noción de «organismo» explica la comprensión, por parte de Nietzsche, de la temporalidad de los eventos históricos.

La relación entre historia y el modelo orgánico no es algo exclusivo del pensamiento de Nietzsche. Antes de él ya Herder había iniciado una campaña naturalizante de la historia humana pues la había colocado en el mismo espectro que el de la historia natural. La inclusión de lo humano en lo natural

1 Basta con echar un vistazo a la literatura secundaria que estudia la relación entre Nietzsche y la ciencias de la vida para darse cuenta de la gran influencia que científicos como Boscovich, Wilhelm Roux, Johannes Müller, Carl von Nägeli, el propio Darwin, etc., ejercieron sobre nuestro autor. También resulta importante tener en cuenta a otros filósofos a través de los cuales Nietzsche adquirió conocimientos sobre las ciencias naturales de la época, como Otto Caspari, Maximilian Drossbach, Otto Liebmann, Lange, etc. Para la relación entre Nietzsche y las ciencias de su época se pueden consultar las siguientes obras recientes: Nietzsche and sciences Brobjer/Moore (eds). Nueva York: Routledge, 2016. Emden, Christian, Nietzsche's naturalism: Philosophy and the life sciences in Nineteen century. Cambridge: Cambridge University Press, 2014.

2 Wolfang Müller Lauter era de esta misma opinion y por ello sostiene que: «También las formaciones sociales son para él [Nietzsche Z.O.] organismos. Por ello ya desde 1881 podía proponerse utilizar 'los últimos organismos, cuya formación presenciamos'- y por éstos entiende Pueblos, Estados, Sociedades- 'como medio de conocimiento de los primeros organismos'. [...] Que todo ser ostenta, con una estructura básica similar, el carácter de la organización y, así, del orden jerárquico del mando, representa para él, a lo largo de toda su obra,una cuestión fuera de toda duda»(mi traducción). MüllerLauter, «Der Organismus als innere Kampf. Der Einfluß von Wilhelm Roux auf Friedrich Nietzsche»: Nietzsche-Studien 7 (1978), pp. 189-235, p. 221.

3 Bertino, Christian. «Vernatürlichung»: Ursprünge von Friedrich Nietzsches Entidealisierung des Menschen, seiner Sprache und seiner Geschichte bei Johann Gottfried Herder. Berlin/Boston: Walter De Gruyter, 2011, p 36.

4 Nietzsche, Fragmentos póstumos Vol. IV 1885-1889. Traducción, introducción y notas de Juan Luis Vermal y Juan B. L Linares. Tecnos, 2006. Citado FP IV 237, 9 [8]. 
le permitió a Herder comprender la historia humana como un movimiento que reproducía a la escala de los pueblos, el movimiento de un embrión en formación (epigénesis) ${ }^{5}$. Sin embargo, a pesar de esta convergencia entre la empresa herderiana y la nietzscheana ${ }^{6}$, esta última posee rasgos característicos, empezando por el rechazo de la comprensión de lo orgánico como un movimiento teleológico.

Para entender esta nueva concepción de la historia entendida como fenómeno orgánico no teleológico es necesario comprender qué es exactamente lo que Nietzsche entiende por «organismo». No obstante, para hacerlo es necesario entender, en primer lugar, el concepto fundamental que lo explica, a saber, el de fuerza.

\section{LA DISCUSIÓN EN TORNO AL CONCEPTO DE FUERZA}

Es importante comprender que el concepto de fuerza ha adquirido distintas valencias a lo largo de la historia de la filosofía, principalmente a partir de Leibniz. El concepto leibniciano de «vis» es, según el propio Leibniz, una reinterpretación del concepto aristotélico de entelecheia ${ }^{7}$, el cual, como es claro, lleva implícita la idea de telos. Pero contrariamente al Aristóteles de Sobre la generación, para quien la entelecheia indica la actualización de una forma, es decir, el arribo de un organismo a su forma final, lo cual lo hace capaz de producir otro individuo igual a él ${ }^{8}$, el concepto de fuerza en Leibniz es, como también afirma el propio autor, un mero principio heurístico ${ }^{9}$ que significa, más que fin alcanzado, un esfuerzo o tendencia ${ }^{10}$.

De acuerdo con Aristóteles en un organismo tienen lugar procesos teleológicos de crecimiento interno, es decir, una «cascada de cambios graduales dentro de una masa indiferenciada que tiene como consecuencia la constitución de un todo bien organizado» ${ }^{11}$. Dichos procesos se realizan por la acción de una causa final que opera al interior del propio organismo.

5 Ver. Herder, J. G. Ideen zur Philosophie der Geschichte der Menschheit, XV, ii, p. 411-412. Tomo 2. Berlin/ Weimar: Aufbau, 1965.

6 De hecho Bertino analiza precisamente la convergencia de ambos proyectos así como los puntos de divergencia. Ver Bertino, op. cit.

7 Ver Leibniz, Specimen dynamicum, trad. Carlos Másmela Arroyave. Primera parte publicada en Estudios de Filosofia, 5 (1992) pp. 105- 113, p. 106, 107.

8 Ver Aristóteles, Generation of animals, trad. A. L. Peck. Londres: William Hainemann LTD/ Harvard University Press, 1943, 734 b.

9 Leibniz, op. cit. p. 107.

10 Ver Pérez Quintana, Antonio, «Fuerzas, tendencias, entelequias: vida y finalidad inmanente según Leibniz»: Thémata. Revista de Filosofia, 42 (2009), pp. 137-153, p. 144.

11 Van Speybroeck, de Waele, van de Vijver, «Theories in Early Embryology Close Connections between Epigenesis, Preformationism, and Self-Organization»: Annals of the New York academy of sciences, 981/7 (2002), pp. 1-49, p. 9 (mi traducción). 
Ciertamente para Leibniz la fuerza no debe ser entendida como una mera facultad o una mera potencia que necesite ser estimulada desde el exterior para poder, así, actuar. Más bien la fuerza debe entenderse, como en Aristóteles, como una cierta causa final. Sin embargo la fuerza inherente a las cosas no es para el filósofo de Hannover una actividad plena, pues aun incluso contando con su propia teleología interna y su capacidad de cambiar, las sustancias carecen de la fuerza interna necesaria para cambiar por sí mismas. La insuficiencia de las fuerzas llamadas «derivadas» se atenúa gracias al postulado de una fuerza llamada «primigenia». Ésta es el principio de acción propiamente dicho ya que actúa sobre las fuerzas derivadas sin ser lo mismo que ellas. ${ }^{12}$ Esto hace de la fuerza en Leibniz algo que es al mismo tiempo trascendente e inmanente ${ }^{13}$ y este es quizá el punto de mayor divergencia entre él y Aristóteles.

Günter Abel resalta con pertinencia la importancia de Leibniz para el pensamiento nietzscheano sobre la fuerza pero prudentemente afirma que, a pesar de las similitudes, sería erróneo equiparar la postura de ambos con respecto a dicho concepto. ${ }^{14}$ Pensar que hay influencia de Leibniz sobre Nietzsche se justifica teniendo en cuenta que el concepto leibniciano de fuerza estuvo implicado en la configuración de importantes teorías fisiológicas, químicas y físicas. ${ }^{15}$ Boscovich es un ejemplo de la influencia de Leibniz en las ciencias y es a su vez uno de los puentes más directos entre el filosofo de Hannover y nuestro autor. Sin embargo, dicho puente no implica, paradójicamente, continuidad, sino distancia.

Para Boscovich, como para el Leibniz del Specimen Dynamicum, todo es fuerza. Sin embargo, a diferencia de Leibniz, Boscovich no considera que los cuerpos sean el fundamento a partir del cual hay que pensar la fuerza, sino al contrario: la fuerza debe de ser considerada la condición de la materia ${ }^{16}$. Nietzsche, basándose en Boscovich, rechaza toda idea de mónada material o la teoría atómica mecanicista ${ }^{17}$. El átomo representa un bastión fundamental del materialismo- su pieza última, irreductible. Nietzsche dice: «Absoluta exclusión del mecanismo y de la materia: ambos sólo formas de expresión de

12 Leibniz dice : «No hay [...] Genios sin cuerpos. Únicamente Dios se encuentra enteramente desapegado». Discours de métaphysique suivi de Monadologie, Paris: Gallimard, 1995, §72, p. 109110 (mi traducción). Como se percibe, sigue habiendo en Leibniz un abismo infranqueable entre la fuerza pasiva - que es materia viva- y la fuerza activa o primitiva, que es el alma.

13 Pérez Quintana, lo.cit., p. 139.

14 Abel, Günter, Nietzsche. Die Dynamik der Willen zur Macht und die ewige Wiederkehr. Berlin/ New York: De Gruyter, 1998, p. 6

15 Como por ejemplo en la teoría epigenética de Caspar Friedrich Wolff. A propósito, ver Roe, Shirley «Rationalism and Embryology: Caspar Friedrich Wolff's theory of Epigenesis»: Journal of the history of biology 20 (1979) pp. 430-438.

16 Ver Abel, op. cit., p. 84.

17 Ibid., p. 86. 
grados inferiores, la forma más desespiritualizada del afecto ('de la voluntad de poder')». 18

A diferencia de Leibniz, y también de Aristóteles, las fuerzas, para Nietzsche no se encuentran ni dentro de algo (la materia), ni impulsan algo distinto de ellas. No hay para Nietzsche algo así como fuerzas formadoras [bildende Kräfte] dentro de un organismo, responsables de hacerlo llegar a ser lo que el organismo debe ser, según su causa ideal-final.

Ciertamente, las fuerzas crean efectos y sólo de esta manera son realmente efectivas. Sin embargo, su producción de efectos no depende de su acción sobre algo distinto a ellas, sino de su relación con otras fuerzas; por ello puede hablarse, como afirma Abel, de relaciones efectuales entre ellas (Wirkrelationen). ${ }^{19}$

La relación entre las fuerzas no es, entonces, una producción causal de efectos sino, más bien, una combinatoria. En este orden de ideas, los cuerpos deben ser comprendidos como manifestación de fuerza ${ }^{20}$ y no como materia sobre la cual se ejercen poderes que la transforman. Por todo lo anterior Nietzsche afirma:

Un quantum de fuerza es justo un tal quantum de pulsión, de voluntad, de actividad- más aún, no es nada más que ese mismo pulsionar, ese mismo querer, ese mismo actuar $[\ldots]$ no hay ningún 'ser' detrás del hacer, del actuar, del devenir; 'el agente' ha sido ficticiamente añadido a hacer, el hacer es todo [...] los investigadores de la naturaleza no lo hacen mejor cuando dicen 'la fuerza mueve, la fuerza causa' y cosas parecidas,- nuestra ciencia entera, a pesar de toda su frialdad de su desapasionamiento, se encuentra sometida aún a la seducción del lenguaje y no se ha desprendido de los hijos falsos que se le han infiltrado, de los sujetos (el átomo, por ejemplo, es uno de esos hijos falsos, y lo mismo ocurre con la kantiana 'cosa en sí'). ${ }^{21}$

Con la cita anterior Nietzsche deja en claro que la idea de la fuerza como lo agente diferenciado de un paciente produce la idea de sujeto y de algo que dura. Pero como también se entiende a partir de su crítica a esta idea, para nuestro autor no hay una diferencia entre el ser y el hacer, entre actuar y padecer; además, la relación efectual entre las fuerzas no posee voluntad de conservarse, lo cual apunta a la configuración de toda una nueva economía de la vida.

En ciertas afirmaciones propias de la teoría celular según las cuales

18 FP IV 237, 9 [8].

19 Ver Abel, G. op.cit., p. 8.

20 Ibid., p. 20.

21 Nietzsche, F. Genealogía de la moral, trad. Andrés Sánchez Pascual. Madrid: Alianza, 2002. 1, §13. p. 60. Citado GM 
el protoplasma está lejos de contar con una regulación armónica interna ${ }^{22}$, Nietzsche cree encontrar la refutación a la idea de voluntad de autoconservación. El ejemplo del protoplasma le sirve para demostrar que la sustancia vital y, generalizando, la vida misma, es siempre un incorporar elementos externos, un extenderse más allá y un constante desgaste de recursos. Al respecto sostiene:

No se puede derivar la actividad más básica y originaria del protoplasma a partir de una voluntad de autoconservación; pues éste absorbe de una manera absurda más de lo que le exigiría su conservación; y sobre todo no «se conserva»al hacerlo, sino que se descompone $[\ldots] .^{23}$

Podría decirse que para Nietzsche el principio que rige las fuerzas es el de la prodigalidad, el del desgaste y la desmesura. Por ello es incapaz de sostener que en la fuerza habría ya un plan o que ésta estaría ya programada y serviría para formar y desarrollar algo de determinada manera. Asumir lo anterior implicaría fijarle límites a su poder-crecer, lo cual es contrario a la idea de exceso, justificada por la actividad del protoplasma.

\section{ORGANISMO. Un CONCEPTO SIN TELEOLOGÍA}

La manera en la que Nietzsche entiende el concepto de fuerza incide directamente en su comprensión del organismo. Así, contrariamente a una lectura teleológica hecha posible por la idea de fuerza como principio organizador y director, para Nietzsche el organismo no es algo que posea «intención», que cumpla un fin preestablecido y que esté delimitado en su poder. Los organismos son, más bien, arenas o un campos de lucha entre una multiplicidad de fuerzas.

A estos campos de lucha Nietzsche los llama organizaciones de poder [Macht-Organisationen]. Cada una de estas organizaciones es una perspectiva; ello es equivalente a sostener que cada una de ellas, si bien posee un cierto tipo de especificidad o de singularidad, no son formaciones permanentes. La manera en la que Nietzsche explica cómo se forman dichos centros de fuerzas es la siguiente:

De acuerdo con mi representación, cada cuerpo específico aspira a dominar el espacio entero y a extender su fuerza (- su voluntad de poder) y a repeler todo lo que se opone a su expansión. Pero tropieza constantemente con aspiraciones

22 Emden sostiene que Nietzsche encontró en el libro de Roux Der Kampf der Theile im Organismus, ejemplos que justificaban dicha teoría, aunque también puede hablarse de la influencia de Emanuel Herrmann, «Das Gesetz der Vermehrung der Kraft». Emden, Ch. op. cit., nota 61, p. 183. Y refiriéndose a Roux Emden afirma que para el científico, los procesos orgánicos mostraban una «sobrecompensación» y que tendían a usar más energía de la estrictamente necesaria. Emden, op. cit. p. 178

23 FP IV 401, 11 [121]. 
iguales de otros cuerpos y acaba arreglándose («uniéndose») con aquellos que le son bastante afines:- así conspiran entonces juntos para lograr el poder. Y el proceso continúa $[\ldots]^{24}$.

Esta explicación parecería movilizar la idea de átomo o de sujeto, en tanto que cuerpo. Sin embargo, teniendo en cuenta la crítica al atomismo y al subjetivismo, estamos autorizados a entender esta «unión» entre cuerpos, esta conspiración para mantener el poder, como una unión transitoria de elementos que están diferenciados también transitoriamente. El organismo no es un conjunto de fuerzas que se auto-desarrolle, sino un conjunto de fuerzas configurando una situación, un evento orgánico.

De este modo el organismo debe ser entendido, más que como una sola fuerza autoproductora, como un conjunto (no determinado) de fuerzas que hacen organismo ${ }^{25}$. Este organismo posee límites difusos; en él cada quantum de fuerza lucha por apoderarse de los demás para fijar así -al menos momentáneamente- una configuración de lo que Nietzsche llama «sentido». Un organismo es una configuración momentánea o, como Nietzsche dice: «una relativa duración en el seno del devenir». ${ }^{26}$ Las funciones de dominio, o fuerzas avasallantes que otorgan sentido a un organismo, no son incompatibles con las clásicas funciones del organismo como lo son la de crecer, madurar o morir $^{27}$; pero ese proceso vital dejará de ser comprendido por Nietzsche como un proceso teleológico.

El que las fuerzas impongan funciones podría parecer incompatible con la crítica a la teleología ya que si las funciones imponen un «para», parecería que las fuerzas conservan una cierta finalidad: una función para algo. Sin embargo no hay que olvidar que, según Nietzsche, las fuerzas configuran su efecto a partir de la relación con las demás ${ }^{28}$, no antes. Por ello las funciones de dominio no son un «para» previo a la relación en la que se encuentren. Además de ser momentánea, esta unión tiene un efecto sobre los cuerpos conspiradores, a saber, su disolución en tanto que tales y la creación de un

24 Ibid., IV 603, 14 [186].

$25 \mathrm{Al}$ respecto Abel dice: «Cuando los impulsos se constituyen, en primer lugar, de manera plural $[\ldots]$ cuando $[\ldots]$ el alma es interpretada como una construcción colectiva de impulsos y afectos y cuando, finalmente, la corporeidad humana, el todo orgánico del cuerpo, se determina como construcción colectiva de muchas almas, ello quiere decir que al interior del constructo dado que entendemos como unidad de relativa durabilidad y estabilidad, tiene lugar un permanente y multiforme ser-activo. En él no es esencial que cada uno de sus elementos se conserve; se trata más bien de aumento, de más poder. (Mi traducción). Abel, G., op. cit, p. 84.

26 FP IV 388, $11[73]$.

27 GM, II, §3, pp. 79-81.

28 Esta es una observación que John Richardson también hace en Nietzsche 's new Darwinism. Oxford: Oxford University Press, 2004, pp. 36-52. 
orden en donde cada uno tiene una valencia particular específica. Lo que la organización transitoria de poder configura es el resultado de una lucha de fuerzas que, lejos de obedecer a un plan de desarrollo establecido y contenido en el interior del organismo, es el producto de circunstancias contingentes. Dado que su configuración está basada en un proceso agonal, la configuración final es imprevisible.

A pesar de todo lo anterior, con el concepto de organismo entendido como una lucha interna azarosa, Nietzsche no descarta que se pueda seguir hablando en términos de desarrollo. Esta observación es importante en relación a la historia. Sin embargo este concepto deberá ser entendido según las funciones orgánicas a las que acabamos de hacer referencia y no a partir de su concepción en la tradición del pensamiento alemán clásico.

\section{EL CONCEPTO DESARROLLO, UN CONCEPTO DEMASIADO ALEMÁN}

En un famoso pasaje leemos: «[...] lo que la filosofía alemana ha dado a Europa es precisamente el concepto de desarrollo» ${ }^{29}$. Como sostiene Nietzsche, este concepto ha tenido tanto éxito que se ha exportado de Alemania hasta alcanzar las tierras insulares del pensamiento inglés, influyendo fuertemente a Darwin. Nietzsche llega incluso a afirmar que sin la enseñanza hegeliana sobre el desarrollo del concepto, Darwin no hubiera sido posible (ohne Hegel kein Darwin $)^{30}$. Según Ernst Mayr es, en efecto, acertado suponer que sin la tradición alemana el evolucionismo tal y como Darwin lo definió, no hubiera sido posible ${ }^{31}$.

La tradición alemana de la que Darwin abreva incluye no sólo a la escuela de Göttingen, de donde provienen la mayoría de los fisiólogos que desencadenaron la discusión sobre la epigénesis contra el preformacionismo que, según Mayr, Darwin zanjó, sino que también incluye a Herder y a la tradición que con él se inauguró (incluyo aquí a los hermanos Humboldt, y en particular a Alexander v. Humboldt, a quien Darwin tuvo en muy alta estima ${ }^{32}$.

Podríamos decir que Hegel es el colofón de esta tradición herderiana, en cuya filosofía perviven de manera clara, elementos de las ciencias naturales no ya solo en su filosofía de la naturaleza sino en la propia constitución interna de su ontología. Pero para justificar una afirmación de apariencia tan irrecusable-

29 Nietzsche, F. La Gaya ciencia, tr. y prol. Charo Greco y Ger Groot, Madrid: Ediciones Akal, 2001, $\$ 357$ p. 276. Citado GC.

30 Ibid.

31 Mayr, Ernst, The growth of biological thought. Diversity, evolution and inheritance. Londres: The Belknap press of Harvard University Press, 1982, p. 101-104. Y Werner Stegmeir «Ohne Hegel kein Darwin» en Volker Gerhardt/RenateReschke (eds), Nietzsche, Darwin und die Kritik der Politischen Theologie, Nietzscheforschung, 17. Berlin: Akademie Verlag, 2010, p. 74.

32 Mayr, E., op. cit., p. 397. 
ohne Hegel kein Darwin- hace falta no haber reconocido previamente una diferencia tan fundamental entre ambos pensadores como la que establece el concepto de variación y la ausencia de necesidad en Darwin. ${ }^{33}$

La exposición detallada de las múltiples e importantes diferencias entre el pensamiento de Darwin y el de Hegel no puede ser llevada a cabo aquí. Tampoco es posible detenernos en la interpretación de Nietzsche respecto de la relación entre la filosofía hegeliana y la teoría evolucionista de Darwin. Aquí sólo me interesa poner de relieve lo que Nietzsche extrae de esta (desatinada) genealogía, es decir, sólo quiero señalar que, en general, Darwin es acusado por Nietzsche de perpetuar la «mistificación» hegeliana de la historia que consiste en humanizar el proceso evolutivo mediante la adjudicación de una finalidad moral a la vida. Esta mistificación justifica, según Nietzsche, el recurso a conceptos como «utilidad» o «lucha por la supervivencia» en las tesis de Darwin. Esta supuesta moralización de la vida por parte de Darwin proviene, según Nietzsche, de la incomprensión de la manera en la que la vida se desarrolla.

Recordemos que Nietzsche toma como modelo de la vida en general el caso del protoplasma. En este sentido, como ya vimos, la vida es puro exceso y no tiende a nada, mucho menos a la conservación de sí, ni a la instauración de un orden moral-político en donde sólo un tipo de ser humano (el más apto) pudiese prosperar. Respecto de la autoconservación Nietzsche insiste en que:

Los fisiólogos deberían pensárselo bien antes de afirmar que el instinto de autoconservación es el instinto cardinal de un ser orgánico. Algo vivo quiere, antes que nada, dar libre curso a su fuerza. - La vida misma es voluntad de poder-: la autoconservación es tan sólo una de las consecuencias indirectas y más frecuentes de esto ${ }^{34}$.

Las críticas que Nietzsche lanza contra los naturalistas, biólogos y fisiólogos de su tiempo ponen en evidencia una observación que se repite como un eco en varias afirmaciones con respecto a la ciencia en general: ésta es para Nietzsche una construcción teórica macerada en moralidad ${ }^{35}$. La crítica

33 A pesar de todas sus críticas y de la filiación intelectual que Nietzsche se limita a sugerir entre Darwin y su archienemegio Hegel, el pensamiento nietzscheano coincide con el de Darwin en tesis importantes. Una de ellas es la idea según la cual, si bien el organismo no tiene una meta, se le debe concebir como una tendencia a adquirir su propio empoderamiento. Esto es lo que Richardson llama la dinamización del criterio de selección natural de Darwin (Richardson, op. cit., p.61). También coinciden en la idea de que la vida no tiene una temporalidad repetitiva de lo mismo. No hay repetición de lo mismo en la reproducción de la especie- como Hegel, por otro lado, parecía concebir en la naturaleza- sino que, según las circunstancias, la especie puede variar.

34 Nietzsche, F. Más allá del bien y del mal, trad. Andrés Sánchez Pascual. Madrid: Alianza, 2003, § 13, pp. 36-37. Citado MABM.

35 Nietzsche dice: «Estos biólogos prolongan las estimaciones de valor morales (el valor en sí 
a la idea de la autoconservación como finalidad de la vida, idea moral que le atribuye una intención, también se aplica al darwinismo social de H. Spencer y E. Haeckel. A pesar de que para Nietzsche la mayoría deba servir para engendrar individuos más perfectos, el resultado de la generación exuberante no es moralizado. Lo que interesa a Nietzsche no son las especies ${ }^{36}$ sino sólo individuos. Es a partir de ellos que debe concebirse el principio de la vida ${ }^{37}$. Por ello también afirma:

Principio de la vida. Errores básicos de los biólogos hasta el momento: no se trata de la especie sino de individuos que actúan con más fuerza (el gran número es sólo un medio). La vida no es adaptación de condiciones internas a condiciones externas sino voluntad de poder que, desde el interior, somete e incorpora a sí cada vez más «exterior» ${ }^{38}$.

Con lo anterior podemos apreciar que Nietzsche está en contra de la moralización de la biología. Así, para llevar a cabo su proyecto de naturalizar lo humano, es necesario desmoralizar la biología y la vida misma. Veamos a continuación cómo contrasta el concepto de desarrollo propiamente nietzscheano con el concepto alemán por excelencia.

IV. EL CONCEPTO NIETZSCHEANO DE DESARROLLO Y SUS IMPLICACIONES EN LA

\section{DEFINICIÓN DE LA HISTORIA}

Si el desarrollo no es un progreso teleológico y eficaz, entonces ¿cómo lo entiende Nietzsche? Expondremos las etapas que creemos encontrar en los organismos nietzscheanos.

Un acontecimiento o un organismo es producto de un desarrollo, pero la génesis y el desarrollo de un organismo ya no pueden ser considerados como el progreso de una cosa hacia sí misma. En acuerdo con lo anterior Nietzsche sostiene:

El «desarrollo» de una cosa, de un uso, de un órgano es, según esto, cualquier cosa antes que su progressus hacia una meta, y menos aún un progreso lógico y brevísimo, conseguido con el mínimo gasto de fuerza y de costes, - sino la sucesión de procesos de avasallamiento más o menos profundos, más o menos independientes entre sí que tienen lugar en la cosa, a lo que hay que añadir la resistencias utilizadas en cada caso para contrarrestarlos, las metamorfosis

superior del altruismo, la hostilidad contra el ansia de dominio, contra la guerra, contra la inutilidad, contra el orden jerárquico y estamental)». FP IV 212, 7 (9).

36 En Hegel lo importante tampoco son las especies pero sí el Género, en sentido lógico-ontológico.

37 Por eso Nietzsche afirma: «error de los biólogos- sólo hay individuos, no especies». Idem.

38 Ibid, 211. 
intentadas con una finalidad de defensa, de reacción, así como los resultados de contraacciones [Gegenreaktionen] afortunadas $[\ldots]^{39}$.

Vemos entonces que el desarrollo de un organismo no es un progreso que tenga una finalidad preestablecida. En lo que Nietzsche acaba de afirmar se expresa nuevamente el rechazo a la causalidad final que, como hemos visto, implica la separación entre lo que una fuerza puede y lo que es, haciendo de eso «que es» un «aún no ser» (pues para ser hay que alcanzar su potencia y actualizarla). Como hemos visto también, una fuerza es para Nietzsche aquello que es ya siempre lo que puede, pero no porque las fuerzas sean idénticas a sí mismas y cuenten siempre con una misma valencia, sino porque se encuentran ya siempre en relación con otras y siempre se determinan en función de las combinaciones que les tocan en suerte.

Por lo anterior el desarrollo de un organismo no es ni lógico ni breve, no sigue una regla como la de la no contradicción y está lejos de ser el resultado inmediato de una operación aritmética (suma de etapas). El desarrollo no es un proceso eficiente que tuviera lugar de la manera más ventajosa e inmediata para lo que se desarrolla, antes bien es un movimiento natural que está sometido a la contingencia (pues las fuerzas se agregan pero también se separan). Recordemos que la teoría del protoplasma indica que en la naturaleza hay desperdicio de recursos. La naturaleza, en este contexto, no obedece a una economía eficiente y ahorradora. El desarrollo de los organismos debe pensarse, entonces, como un movimiento aleatorio, de duración variable, y en un escenario de desgastes de energía que tiene poco que ver con usos razonables de ésta.

Los organismos no son unidades estables sino configuraciones más o menos fijas que experimentan, en conjunto, la agregación más o menos independiente de otras fuerzas, de otras circunstancias. Como ya también se indicó, debemos también guardarnos de comprender por «organismos» unidades bien delimitadas, individualidades con bordes definidos, dentro de los cuales aconteciera el desarrollo. Los organismos a los que Nietzsche se refiere son cosas difíciles de definir pues no son elementos discretos y fijos; no son unidades estables, sino conjuntos variables. En relación a la dificultad de definir lo que un organismo es, es pertinente traer a cuento la siguiente afirmación: «Lo que puede definirse es solo que aquello que carece de historia» ${ }^{40}$. Con esta afirmación quiero indicar que es gracias a la idea del desarrollo orgánico como podemos comprender el concepto de historia en Nietzsche.

La historia se perfila, así, como el conjunto de modificaciones azarosas

39 GM., II, 12, p. 100.

40 Ibid. II, 13, pp. 102-104. 
que experimenta un organismo, un individuo, lo cual la convierte en un fenómeno natural. Pero hay que ser cuidadosos a la hora de interpretar lo anterior ya que, como se ha visto, las modificaciones no las sufre un individuo o un organismo ya creado sino que se constituye en y por sus variaciones, hasta perecer. Los cambios que tienen lugar en las cosas a partir de las pérdidas, los agregados, el desperdicio de energía y la lucha de centros de fuerza, constituye la definición del concepto de desarrollo como crecimiento. El desarrollo debe ser entendido como el hacer organismo, lo que a su vez significa, como hemos visto, encontrarse el conjunto de fuerzas más o menos regular, en un constante proceso de avasallamiento.

Como habíamos indicado líneas arriba, el que una fuerza o una organización de voluntad de poder quiera más poder se contradice con el supuesto de que todo en la naturaleza tiende a querer conservarse. La voluntad de poder, como el impulso de todos los impulsos, $\mathrm{y}$, en general, como el impulso que domina todas las formaciones de poder, lleva, como hemos visto, a la «unión» de diferentes centros de fuerzas, es decir, los lleva a conspirar juntos, pero no, nuevamente, para conservarse, sino para desgastarse.

Durante el crecimiento de un órgano ocurren cambios, pero dichos cambios no dependen, como se sigue de la definición de fuerzas de Nietzsche, de un orden o una potencia inherente a lo que se desarrolla. El crecimiento y los cambios que tienen lugar son producto de la expansión de un orden. La expansión de un organismo no implica la desaparición de otros grupos o centros de fuerza sino su integración y su sometimiento a un nuevo orden de dominio. Este nuevo orden impone, después de una lucha, nuevas funciones a las fuerzas asimiladas. El resultado de la lucha de fuerzas es la fijación de un tipo y su «hacerse fuerte» ${ }^{41}$. Como se sigue de todo lo anterior ese «hacerse fuerte» es producto de batallas, de expansión, de integración o incorporación de lo exterior y no de una finalidad preestablecida.

El movimiento teleológico no se aplica, para Nietzsche, ni a los individuos ni a la historia de algo que podríamos llamar «humanidad». Por el contrario, se originan a partir del deterioro de las organizaciones de poder. Nietzsche dice: «[...] el siglo XIX no es un progreso con respecto al siglo XVI: y el espíritu alemán de 1888 es un retroceso en relación al espíritu alemán de $1788 \ldots$ La "humanidad" no avanza, ni siquiera existe $[\ldots] \gg .{ }^{42}$

La historia no es un proceso de génesis sucesivas (epigénesis) sino que lo nuevo es el resultado de un proceso de decadencia. ${ }^{43}$ En otras palabras, los acontecimientos históricos, o elementos históricos no se suceden, no

41 MABM $\$ 262$, p.242.

42 FP IV 626, 15 [8]].

43 Ver Müller Leuter, loc.cit, p. 225. 
forman una cadena. Por ello Nietzsche afirma también que: «Los poderes de la historia pueden efectivamente conocerse, eliminando toda teleología moral y religiosa. Tienen que ser los poderes que también actúan en todo el fenómeno de la existencia orgánica $[\ldots] » .^{44}$

Recordemos que la existencia orgánica según es entendida por Nietzsche no obedece a los criterios con los que anteriormente se había explicado lo vivo. El exceso, el azar y el puro poder son elementos fundamentales que constituyen la nueva comprensión nietzscheana de lo orgánico. El descomponerse, además, es el precio que un organismo paga al perder el control de lo que avasalla. Nietzsche parece inferir de ello que la descomposición de un orden de poder genera otro individuo. El autor afirma:

[...] La generación, la desintegración aparece cuando las células dominantes son impotentes para organizar lo que han apropiado. Es la fuerza formadora [gestaltende Kraft] la que siempre quiere tener disponible nuevo «material» (aún más «fuerza»). La obra maestra de la construcción de un organismo a partir del huevo 45

El individuo generado no repite al generador, en este sentido no se trata de una reproducción de lo mismo. En lugar de generación de un individuo en función de una especie, para Nietzsche se trata de la emergencia de individuos nuevos y, en general, de la capacidad de experimentación de la vida misma. ${ }^{46}$ En la La genealogía de la moral Nietzsche utiliza un concepto similar al concepto hegeliano por excelencia, a saber, el de Selbstaufhebung, para referirse al complejo momento de decadencia y nacimiento que le sigue. Pero a diferencia del término hegeliano, la auto-superación de un organismo, o su decadencia y la aparición de un orden nuevo, no obedecen ni a una lógica interna que establezca su relación necesaria con lo posterior, ni a una relación causal entre los elementos internos de la organización anterior y la nueva. En otras palabras, en la organización anterior no están contenidas las semillas del orden que seguirá ${ }^{47}$. La aparición de un orden nuevo implica la modificación de un orden, pero no una modificación simplemente opuesta, o mejor dicho, en contradicción necesaria al orden anterior. En este sentido podemos pensarla

44 FP IV 212, 7[9].

45 Ibid., 97, 2 [76].

46 Ibid. 626, 15 [8]

47 GM, II, 10, p. 94. Stegmaier, al abordar esta cuestión, también insiste en que no se trata del concepto hegeliano. Así, el paso que llevó de la intrincación de la filosofía griega y la religión judía a la religión cristiana no implica una dialéctica necesaria sino que, como afirma el comentarista, se trata de un evento contingente, evolutivo, propio de la singularidad de los elementos en cuestión. Stegmaier, W. loc.cit., p. 80-81. 
como una modificación arbitraria. No obedece a nada salvo a la reunión de un conjunto de fuerzas en donde una de ellas domina a las demás.

Ahora, si bien lo que efectivamente acaece no es necesario, el que algo emerja aprovechando ciertas condiciones que indican la decadencia del orden anterior no constituye una arbitrariedad sino que es incluso algo que obedece a una ley de la vida. Nietzsche dice:

Todas las grandes cosas perecen a sus propias manos, por un acto de autosupresión: así lo quiere la ley de la vida, la ley de la «autosupresión» necesaria que existe en la esencia de la vida, - en el último momento siempre se le dice al legislador mismo: pater legem, quam ipse tulisti [sufre la ley que tú mismo promulgaste]. Así es como pereció el cristianismo, en cuanto dogma, a manos de su propia moral; y así es como ahora también el cristianismo en cuanto moral tiene que perecer,- nosotros nos encontramos en el umbral de este acontecimiento [...] este hecho de que la voluntad de verdad cobre consciencia de sí hace perecer de ahora en adelante- no cabe ninguna duda- la moral: ese gran espectáculo en cien actos, que permanece reservado a los dos próximos siglos de Europa, el más terrible, el más problemático, y acaso también el más esperanzador de todos los espectáculos $[\ldots]^{48}$.

La decadencia de un organismo (p. ej. la moral cristiana) es un espectáculo esperanzador. Nadie sabe qué es lo que pasará, pues el futuro es impredecible. Sin embargo es posible asumir que el nuevo orden que se instalará en la cultura debe ser diferente.

\section{LA VARIACIÓN: UN ASPECTO CONSTITUTIVO DE LA TEMPORALIDAD}

En la biología actual y más específicamente, en la teoría evolucionista, ese cambio súbito que explicaría la transformación de las especies- no de los organismos- no ha podido ser demostrado y, según Mayr, es improbable que ello llegue a suceder. Ello estriba en que resulta imposible pensar en la súbita transformación de todo el código genético en un instante ${ }^{49}$. Sin embargo Nietzsche se refiere a este tipo de cambios como posibles; de hecho para él la generación implica siempre una variación.

La génesis en tanto que variación acaece una vez que la tensión que mantenía un centro de fuerzas avasallando a otras de un organismo decrece. Una vez que ésta se distiende y la dureza de las leyes cede, aparecen las condiciones para que las variaciones ocurran. La aparición de lo nuevo es súbita, la

48 GM, III, 27, p. 203.

49 Ver Mayr, E., Towards a new Philosophy of biology. Cambridge: Harvard University Press, 1988, p. 465. 
condición favorable por excelencia para su aparición es que la especie haya bajado la guardia, por así decir, respecto de amenazas posibles. Nietzsche dice:

Una especie surge, un tipo se fija y se hace fuerte en una larga lucha con condiciones desfavorables esencialmente idénticas. A la inversa [...] un exceso de protección y de cuidado propenden, en seguida, de manera muy intensa, a la variación del tipo y son [las especies] abundantes en prodigios y monstruosidades (también en vicios monstruosos $[\ldots]^{50}$.

La mala conciencia constituye un buen ejemplo de variación. La descripción de su génesis por parte de Nietzsche en La genealogía de la moral sigue los mismos lineamientos a los que Nietzsche había aludido para hablar de apariciones de tipos nuevos en el fragmento que acabamos de citar, a saber, relajación de la tensión en el centro de fuerza avasallante hasta ese momento (la decadencia de un organismo) y la súbita aparición de otro poder, un nuevo poder que exige la reorganización de todo lo anterior:

$[\ldots]$ hipótesis sobre el origen de la «mala conciencia» [...]: modificación ocurrida cuando el hombre se encontró definitivamente encerrado en el sortilegio de la sociedad y de la paz. [...]-de un golpe todos sus instintos quedaron desvalorizados $y$ "en suspenso" [...] - ¡y, además, aquellos viejos instintos no habían dejado, de golpe, de reclamar sus exigencias! Sólo que resultaba difícil, y pocas veces posible, darles satisfacción [...] Todos los instintos que no se desahogan hacia afuera se vuelven hacia adentro - esto es lo que yo llamo interiorización del hombre: únicamente con esto se desarrolla en él lo que más tarde se denomina su «alma» $[. .$.$] La enemistad, la crueldad [...] todo esto vuelto contra el poseedor$ de tales instintos: ése es el origen de la «mala conciencia» [...] resultado de una separación violenta de su pasado animal, resultado de un salto y una caída, por así decirlo, en nuevas situaciones y en nuevas condiciones de existencia [...] Desde entonces el hombre cuenta entre las más inesperadas y apasionantes jugadas de suerte que juega el «gran Niño» de Heráclito, llámese Zeus o Azar ${ }^{51}$.

No hay que olvidar que esta variación está asociada a condiciones circundantes- ausencia de enemigos- y no a algún mal funcionamiento de un improbable Bildungstrieb, el cual es, por definición interior y teleológico. La mala conciencia, así como otros eventos- como el Estado- son apariciones inesperadas que no obedecen a las condiciones o situaciones anteriores aunque, como hemos dicho, sí que aparecen como resultado de condiciones favor-

50 MABM §262, p. 242. Esto marca una posible relación con el hopeful monster de Goldschmidt, precursor de la teoría del puntualismo en genética. Ver Mayr, E. Towards a new philosophy of biology, p. 467.

51 GM II, 16, p. 109-110. Subrayado nuestro. 
ables propiciadas por el debilitamiento o relajación de la tensión del centro de fuerza que mantiene el poder sobre un organismo. Las variaciones son, como Nietzsche señala, accidentes, eventos totalmente inesperados. Sin embargo, a pesar de ser casuales no carecen de un orden sino que son el producto, como ya se ha mencionado, de una ley de la vida ${ }^{52}$ que lleva a las grandes cosas a perecer.

Su aparición inesperada sigue teniendo como consecuencia la imposición de una nueva coacción y el reordenamiento de los elementos anteriores, como es el caso de los instintos del hombre. Dicha coacción es un nuevo orden dentro del cual todos sus elementos constituyentes adquieren un sentido distinto al anterior. La determinación del sentido de los elementos de un nuevo orden no es teleológica sino que se establece en la relación misma del todo gobernada por un tipo de fuerza o centro de fuerza, en constante tensión. En la dimensión ontológica esta emergencia debe entenderse como un salto, como una nueva configuración de fuerzas que vence a la configuración anterior ${ }^{53}$.

Las variaciones también pueden ser consideradas como modificaciones del ensamblaje, que admiten otras fuerzas agregadas que no existían antes. Pero creer que las modificaciones son modificaciones de algo que sobrevive a sus transformaciones es erróneo en el caso de la filosofía de Nietzsche. Por ello la variación no debe entenderse tampoco como la preservación de un evento con modificaciones añadidas. Las variaciones, consideradas históricamente o, mejor dicho y para emplear el término adecuado a la filosofía de Nietzsche, genealógicamente, ciertamente tienen una relación con lo que las precedió pues, como Nietzsche parece implicar, hay vestigios de los órdenes anteriores que se conservan, que pueden seguir teniendo efectos similares (como la práctica del castigo que, inscrita en un orden completamente diferente al de las sociedad antiguas, todavía parece poseer significados ancestrales). Pero un concepto, una práctica, sólo tiene en común con las otras que la preceden, el nombre, pues, como hemos visto estudiando el concepto de fuerza, ésta no cuenta con una identidad propia, independiente de otras fuerzas, sino que se configura en su relación a ellas.

Los «virajes históricos» son el producto de una súbita ruptura y el nuevo orden que imponen posee una duración variable. En ellos tiene lugar una mezcla extraña del antiguo orden, percibido como algo caduco; de variaciones afortunadas, es decir, de individuos eyectados de la órbita que envolvía al

52 Ibid., III, 27, p. 203.

53 Como Stegmaier advierte, Nietzsche apreciaba que en Darwin la posibilidad de pensar en la novedad estuviera abierta. Stegmaier, loc. cit., p. 75. 
orden anterior, vagando como electrones autónomos; y de caos. A continuación Nietzsche describe esos periodos:

En estos virajes de la historia muéstranse juntos y a menudo enmarañados y entremezclados un magnífico, multiforme, selvático crecer y tender hacia lo alto, una especie de tempo tropical en la emulación del crecimiento, y, por otro lado, un inmenso perecer y arruinarse, merced a los egoísmos que se oponen salvajemente entre sí y que, por así decir, estallan, egoísmos que luchan unos con otros «por el sol y la luz» y no saben a extraer de la moral vigente hasta ese momento ni limite ni freno ni consideración alguna. ${ }^{54}$

Esta descripción de la situación que sigue al súbito cambio, al cese del crecimiento de un organismo, es explicado por Nietzsche precisamente como una nueva formación orgánica. Esta temporalidad o rítmica, que podemos calificar de tropical o selvática, se refiere a la lucha entre nuevas fuerzas, lucha que contribuirá a un equilibrio que volverá a romperse pues, si bien la variación es absolutamente azarosa, no es azaroso que haya variaciones sino que, como ya hemos dicho, obedece a una ley de la vida. La variación, en suma, indica la aparición de algo nuevo que puede considerarse una jugada del azar, probablemente ya repetida. Esa combinación y esa configuración son el resultado de una «tirada» de suerte. En realidad lo nuevo no es tal en el sentido de la aparición de una fuerza inexistente, sino en el sentido de una combinación inexistente.

En conclusión, podemos afirmar que para Nietzsche la historia no es un proceso de la humanidad: aquí los tres conceptos (historia, humanidad, proceso) han cambiado o perdido su significado anterior. No podemos afirmar que para Nietzsche la historia sea el desarrollo de la humanidad pues, en primer lugar, como vimos anteriormente, la humanidad es una categoría heurística inexistente (Nietzsche vs. la idea de género). Con ello está descartado que la historia sea un proceso que le concierna. Nietzsche sólo cree que hay individuos, la historia, por lo tanto, será algo propio de ellos y deberá entenderse como el conjunto de eventos que dan muestra de la gran capacidad transformadora $\mathrm{y}$, en general, experimentadora, de la vida incluso en el ámbito social. Por eso Nietzsche afirma:

El aspecto global es el de un inmenso laboratorio experimental, en el que algunas cosas salen bien, dispersas por todas las épocas, e innumerables otras fracasan, desprovistas de todo orden, de toda lógica, de todo vínculo y de toda vinculación [...] ¿Cómo tendríamos derecho de desconocer que el ascenso del cristianismo es un movimiento de décadence? [...] ¿Que la Reforma alemana es una 
recrudescencia de la barbarie cristiana? [...] ¿Que la revolución ha destruido el instinto de gran organización, la posibilidad de una sociedad? [...]. El ser humano no es un progreso con respecto al animal [...]. ${ }^{55}$

La visión biológica de lo que sucede en el mundo, tanto natural como cultural es lo que, a su vez, funda la tesis de Nietzsche sobre otro tipo de temporalidad, la disruptiva. La historia no es, por ello, una sucesión de eventos que se originan los unos a los otros según una ley de causalidad eficiente o mecánica, o bien gracias a una ley de causalidad final, o teleológica; sino un conjunto de eventos con una temporalidad selvática inmanente (crecimiento y desgaste); los cuales están gobernados, a su vez, por la ley de la variación, lo que impone la idea de una temporalidad disruptiva posibilitada por el resultado de la lucha de fuerzas. La ley de la vida es la permanente variación y experimentación. Esta ley define la comprensión de la historia por parte de Nietzsche. 